\title{
VARIATION CHARACTERISTICS IN GROWTH STAGES OF WINTER WHEAT (TRITICUM AESTIVUM L.) AND PREDICTION MODEL
}

\author{
Weili Wang, Xuhui Zhang ${ }^{1}$ and Zhaotang Shang ${ }^{2 *}$ \\ Jiangsu Meteorological Observatory, Nanjing-210008, China \\ Keywords: Stability, Meteorological conditions, Climate change, Prediction model, \\ S-shaped variation curve
}

\begin{abstract}
The variation characteristics of growth stages of winter wheat (Triticum aestivum L.) with the climate change were measured by designing its stability and prediction model. Results showed the trend of stability of growth stage of winter wheat in Jiangsu province of China was an S-shaped curve indicating the growth of winter wheat was more stable in late stage. The lengths of early and late stages of growth were in inverse proportion. Specifically, when the early stage was prolonged, the late stage was shortened, which ensured the relative stability of the length of growth stage. The length of growth stage was correlated with the meteorological conditions. Thus, favorable meteorological conditions contributed to the stability of growth stages of winter wheat. Along with the climate change, the basic statistical characteristics of growth stage remained stable. Each stage drifted moderately under the variation of meteorological conditions, typically during the stage of vegetative growth. The growth process can be regulated by means of variety improvement, adjustment of sowing time and density, reasonable fertilization, and the use of growth regulators. These measures are able to counteract the influences of climate change on winter wheat production and ensure the production security.
\end{abstract}

\section{Introduction}

Wheat (Triticum aestivum L.) is a food crop with huge production amount in the world only second to that of corn. In the context of global warming, the temperature in winter has increased significantly, which affects the growth of winter wheat. For this reason, many researches regarding the influence of climate change on the growth of winter wheat and appropriate measures to combat climate changes have been carried out (Lu and Fan 2013, Johnen et al. 2014). Shang et al. (2013) proposed that climate change increased the susceptibility of winter wheat production, and considered stress-resistance cultivation as a crucial countermeasure, in the aspects of engineering, breeding and management. A widely accepted conclusion is that climate change has caused variations in the growth characteristics of winter wheat. In order to further verify this opinion, a few experiments were conducted to study the influence of climate change on the growth stage (such as occurrence time and duration) of winter wheat, and the subsequent influence on the yield and quality of winter wheat (Shang et al. 2007)

Winter wheat has been cultivated for over 4000 years in China. Many efforts have been made to improve the varieties of winter wheat, with strong resistance, high yield and high quality as the main goals. The whole process of breeding and improving the winter wheat varieties is in essence a response to climate change. Therefore, some scholars believed that the yield and quality of winter wheat are intrinsically determined by the varieties (Gao et al. 2013). In the general context of climate change, how to utilize the correlation between various growth stages of winter wheat, and the potential influence of environmental conditions in the early stage on the growth of winter wheat in late stages to reduce the influence on yield and quality by scientific cultivation and management measures is a subject that requires intensive research. This article analyzed the data of growth stages of winter wheat in Jiangsu monitored by China Meteorological Administration.

*Author for correspondence: <jsqxszt@ 126.com>. ${ }^{1}$ Jiangsu Climate Center, Nanjing 210008, China. ${ }^{2}$ Jiangsu Meteorological Bureau, Nanjing 210009, China. 


\section{Materials and Methods}

The variation of the growth stage of winter wheat mainly refers to the temporal $(t)$ and spatial (s) variation of growth stage. Suppose the starting time of the $\mathrm{i}$-th growth stage is $\mathrm{YDi}(\mathrm{t}, \mathrm{s})$, and the length between two growth stages is $\mathrm{YLi}, \mathrm{i}+1(\mathrm{t}, \mathrm{s})$, then

$$
Y D_{i+1}(t, s)=Y D_{i}(t, s)+Y L_{i, i+1}(t, s)
$$

The temporal and spatial variation characteristics were calculated separately:

$$
\begin{aligned}
& \frac{\partial\left(Y D_{i+1}(t, s)\right)}{\partial t}=Y D_{i}(t)+Y L_{i, i+1}(t) \\
& \frac{\partial\left(Y D_{i+1}(t, s)\right)}{\partial s}=Y D_{i}(s)+Y L_{i, i+1}(s)
\end{aligned}
$$

Statistically, variation coefficient (VC) is a commonly used measure of the relative variation of variables. The variation trend of statistical factors with time is usually expressed by climate trend rate (CTR), which is called relative rate of climate change (RT). The data series of statistical object (DX) is denoted as DXt. Standard deviation is SD, and stability is STA. Thus,

$$
\begin{aligned}
& S T A=V C \times R T \\
& D X_{t}=a+b \times t \\
& C T R=10 \times b \\
& \overline{D X_{t}}=\frac{1}{n} \sum_{t=1}^{n} D X_{t} \\
& S D=\sqrt{\frac{1}{n} \sum_{t=1}^{n}\left(D X_{t}-\overline{D X_{t}}\right)^{2}} \\
& V C=\frac{S D^{2} \mid}{\left|\overline{D X_{t}}\right|} \\
& R T=\frac{|C T R|}{\overline{\left|D X_{t}\right|}}
\end{aligned}
$$

By substituting Eq. (8) into Eq. (9), there is

$$
V C=\sqrt{\frac{1}{n} \sum_{t=1}^{n}\left(\frac{D X t}{\left|\overline{D X_{t}}\right|}-1\right)^{2}}
$$

The growth of winter wheat is under the influence of internal and external conditions. Suppose the growth of winter wheat is $\mathrm{Y}$, and the influence from the intrinsic characteristic is $\mathrm{YS}$, and that from the meteorological condition (X) is YM. Thus,

$$
Y_{i}=f(Y S, Y M)
$$

The linear relationship of these indexes can be expressed as follows:

$$
Y_{i}=a+b \times Y S+c \times Y M
$$




$$
\begin{gathered}
Y S_{i}=a_{i}+\sum_{j=1}^{i-1} b_{j} \times Y S_{j} \\
Y M_{i}=a_{i}+\sum_{j=1}^{n} b_{j} \times X_{i j}
\end{gathered}
$$

For the analysis of spatial variation, the characteristics of the variations of growth stages with longitude and latitude were investigated.

Using linear equation, longitude is denoted as LOG, and latitude as LAT. Thus, Interpolation was performed with GIS to analyze the contours $(\mathrm{CN})$ and plot the distribution diagrams.

$$
D X_{t}=a+b \times L O G+C \times L A T
$$

(1) Data of the growth stage of winter wheat from multiple stations in Jiangsu (Kunshan (KS), Rugao (RG), Dafeng (DF), Xinghua (XH), Xuyi (XY), Huai'an (HA), Binhai (BH), Shuyang (SY), Xuzhou (XZ) and Ganyu (GY)), from 1980 to 2011. The study regions were divided into 4 parts, the whole province (WP), Subei (SB), Suzhong (SZ), and Sunan (SN). The characteristics of each part were statistically analyzed separately (Fig. 1).

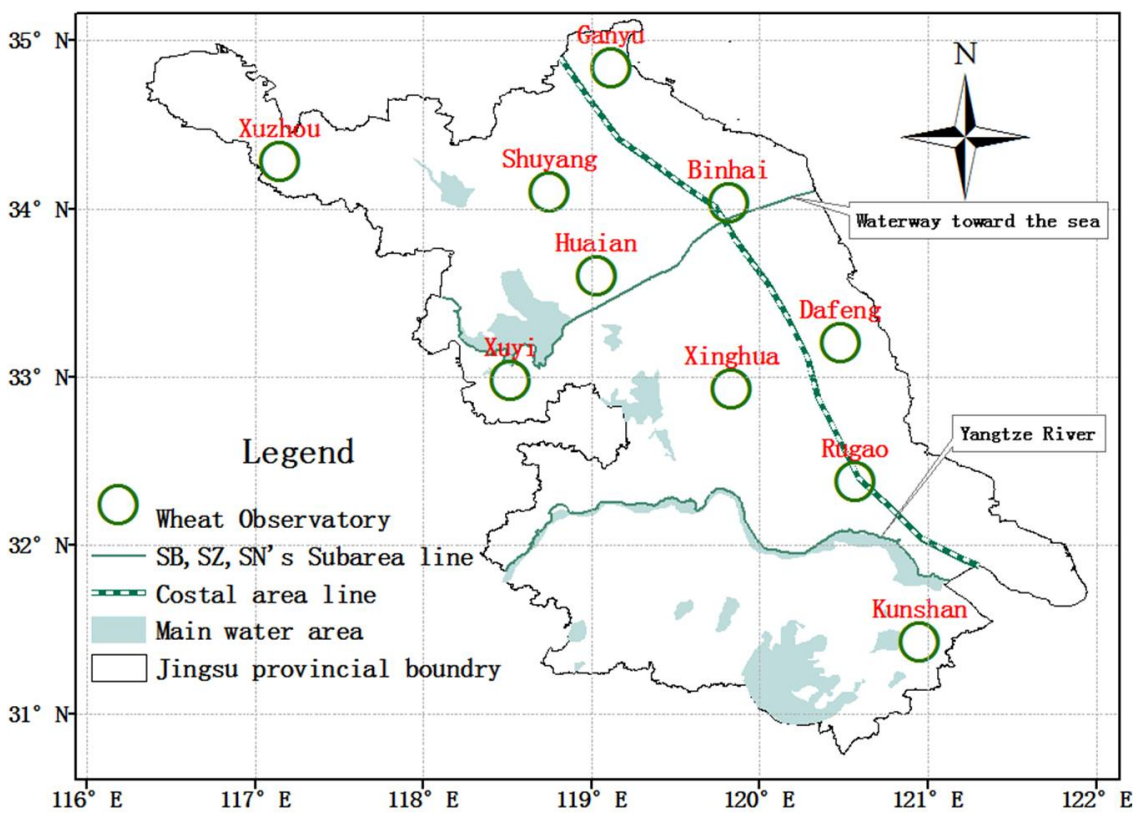

Fig. 1. Subarea and Distribution of observation station.

(2) According to the norms of agricultural meteorological observation stipulated by China Meteorological Administration, the growth stage (GS) was divided into sowing (SOW), sprouting (SPR), triphyllous (TRI), tillering (TIL), over-wintering (OWI), regreening (REG), setting (SET), jointing (JOI), booting (BOO), heading (HEA), anthesis (ANT), milk (MIL) and mature (MAT).

(3) For the sake of convenience, the dates of all stages were converted into date sequence. The dates were numbered from October 1, that is, October 1 was numbered 1, October 2 numbered 2, 
and so on. The length between two growth stages was defined as the interval from the starting date of a stage to the starting of the next stage. For example, the sowing date of Binhai in 1996 was October 15, and the sprouting date was October 22, then the time from sowing to sprouting was $7 \mathrm{~d}$. The full life cycle of wheat was considered as one year, and the data of growth stages of every five years were averaged for statistics. As a result, the data of winter wheat were divided into seven time periods, 1980-1984, 1985-1989, 1990-1994, 1995-1999, 2000-2004, 2005-2009, and 20102011. The interannual means were calculated. These groups were numbered as $1,2, \ldots, 7$ successively. The variations of 5-year means of winter wheat were examined across the groups.

\section{Results and Discussion}

(1) The relationship between the starting time of the stage and the number of the stage (Table 1) was obtained by numerical simulation:

$$
Y D_{w p}=\frac{260}{1+e^{2.787972-0.424144 i}}
$$

where $\mathrm{R}=0.99293>\mathrm{RN}-2=11, \mathrm{a}=0.05=0.553$, and the difference was significant. The diagram was plotted using the theoretical values calculated by Eq. (15) and the measured values (Fig. 2). It can be seen from Fig. 2 that the theoretical values of the stages of winter wheat in Jiangsu were close to the measured values. The stability of growth stage of winter wheat presented an $\mathrm{S}$ shape, which indicated that the characteristics of growth stage of winter wheat did not change obviously with climate change.

Table 1. Relationship between date serial number on wheat growth stage and latitude and longitude.

\begin{tabular}{crrrrr}
\hline GS & CC $_{\text {DSN,LAT }}$ & CC $_{\text {DSN,LOG }}$ & FRI & CR(LAT) & CR(LOG) \\
\hline Sow & $-0.787^{*}$ & $0.784^{*}$ & LOG & 3.6 & -4.2 \\
Spr & $-0.799^{*}$ & $0.758^{*}$ & LOG & 3.5 & -5.1 \\
Tri & $-0.773^{*}$ & $0.769^{*}$ & LOG & 4.5 & -5.3 \\
Til & $-0.840^{*}$ & $0.828^{*}$ & LOG & 6.3 & -7.7 \\
Owi & $-0.847^{*}$ & $0.762^{*}$ & LOG & 1.8 & -3.6 \\
Reg & $0.636^{*}$ & -0.381 & LAT & 0.4 & 4.1 \\
Set & $0.791^{*}$ & -0.412 & LAT & 1.1 & 5.0 \\
Joi & $0.894^{*}$ & -0.527 & LAT & 0.9 & 7.4 \\
Boo & $0.943^{*}$ & -0.501 & LAT & 1.1 & 5.7 \\
Hea & $0.927^{*}$ & -0.504 & LAT & 0.8 & 4.5 \\
Ant & $0.890^{*}$ & -0.492 & LAT & 0.7 & 4.1 \\
Mil & 0.550 & -0.124 & LAT & 1.7 & 3.7 \\
Mat & $0.892^{*}$ & -0.398 & LAT & 1.3 & 4.5 \\
\hline
\end{tabular}

(2) Table 1 showed that the influence of latitude and longitude on the starting time of the stages could be divided into two phases. The first phase was from sowing to over-wintering. The correlation coefficients between the starting time of stages and the latitude and longitude all passed the significance test. In this phase, latitude had the greatest influence, that is, the stage of vegetative growth was most significantly affected by latitude. All stages came in advance with the increase of longitude, with the change rate of -7.7--3.6 d-o-1 and the average of $-5.2 \mathrm{~d} \cdot 0-1$. The starting of the stages was delayed at higher latitude, with the change rate of 1.8-6.5 d.o-1 and the average of $3.9 \mathrm{~d} \cdot \mathrm{o}-1$. The second phase was from regreening to mature. The correlation coefficients between the starting of $90 \%$ stages and the latitude passed the significance test; no correlation coefficients between the starting of stages and the longitude passed the significance 
test. However, longitude played the dominant role. During the transition from vegetative growth to reproductive growth, latitude played the dominant role. All reproductive stages were delayed at higher latitude and longitude. The change rate with latitude was 0.4-1.7 d.o-1, with the average of $1.0 \mathrm{~d} \cdot \mathrm{o}-1$; and the change rate with longitude was $3.7-7.4 \mathrm{~d} \cdot \mathrm{o}-1$, with the average of $4.9 \mathrm{~d} \cdot \mathrm{o}-1$. The number of stages showing significant correlation with latitude was 2.5 times that of stages showing significant correlation with longitude. This indicated that the occurrence time of growth stage of winter wheat in Jiangsu was mainly controlled by latitude. With the increase of latitude, the growth stage was postponed; with the increase of longitude, the growth stage was postponed before winter and advanced after winter.

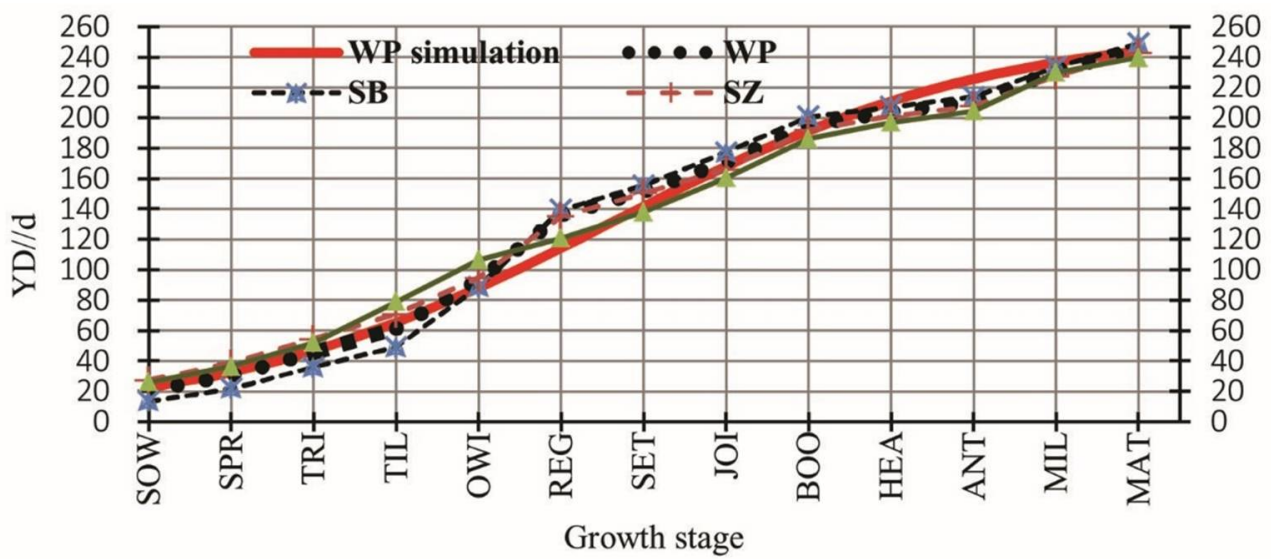

Fig. 2. Trace of date serial number on wheat growth stage. Note: SOW, sowing; SPR, sprouting; TRI, triphyllous; TIL, tillering; OWI, over-wintering; REG, regreening; SET, setting; JOI, jointing; BOO, booting; HEA, heading; ANT, anthesis; MIL, milk; and MAT, mature.

(3) It is apparent from Fig. 3 that the correlation between the starting time of different growth stages of winter wheat can be divided into three phases. The first phase was the period before overwintering, when the starting time of various stages (sowing, sprouting, triphyllous, tillering) was highly correlated. The distribution pattern of correlation coefficients was basically the same as that in later stages. It indicated that the appropriate time of sowing was highly important for the growth of winter wheat before winter. It was the key stage for the cultivation of robust seedlings for overwintering. The second phase was the stage of over-wintering, which was not correlated with any other stages. This indicated that overwintering had little influence on the starting of later stages. The third phase was the period from regreening to mature, with different stages highly correlated. After regreening, the correlation coefficients between the stages showed similar distribution with those for later stages. The starting time of growth stages in vegetative phase and in reproductive phase were highly correlated, respectively. This indicated that in later stages, the influence of the growth status in the early stages increased. Thus, it is more difficult to reverse the growth potential through the cultivation measures in later stages. The correlation coefficient between two stages decreased with the increase of interval between the stages. Thus, the stages would be synchronized sooner or later. That is, when one stage came in advance, the later stages would be accelerated. Therefore, the stages should be adjusted timely to maintain the relative stability of the growth stage and to ensure the yield and quality of winter wheat. 


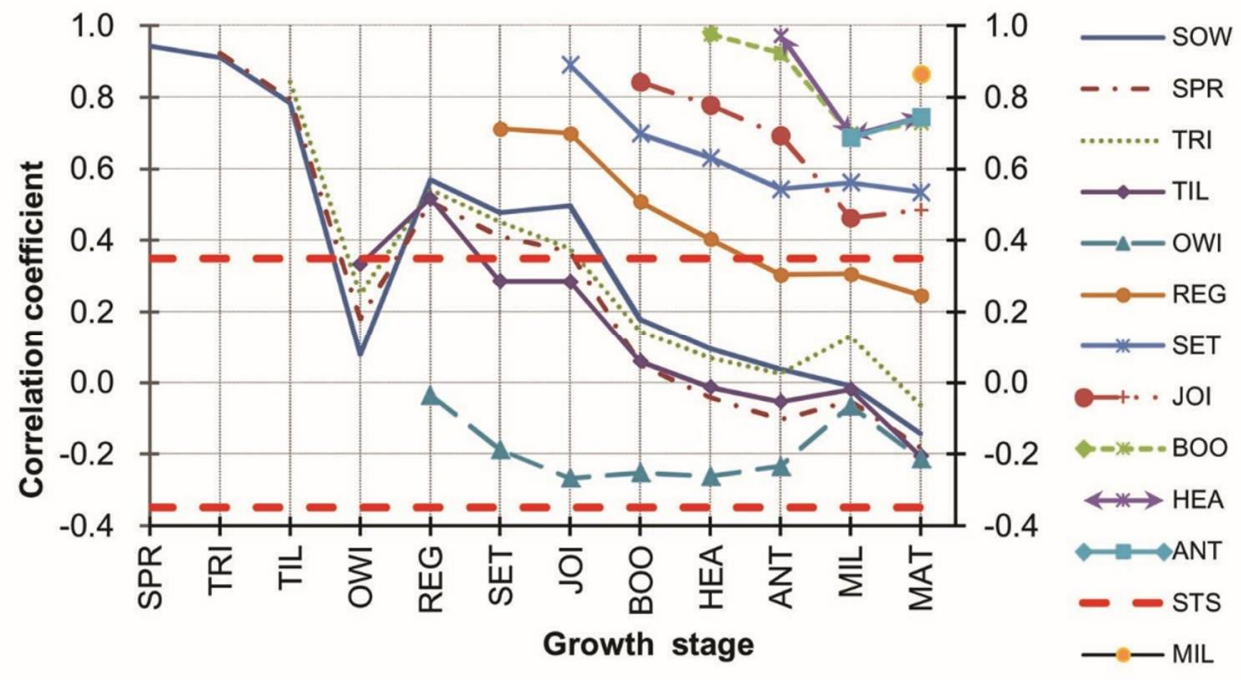

Fig. 3. Correlation coefficient between date serial number on wheat growth stage.

(4) It can be observed from Fig. 4 that the stages before setting were usually postponed due to climate change. The postponing of the vegetative stage is favorable for laying a foundation for the high yielding of winter wheat. The stages from jointing to antithesis were mostly shortened, that is, the stages in the reproductive phase were shortened, which was unfavorable for the formation of large ears; the stability from milk to mature is favorable for the increase of grain weight. The change rate of growth stages relative to climate change was less significant over time (Fig. 4). That is, the influence of climate change on the starting time of the stages was diminished with
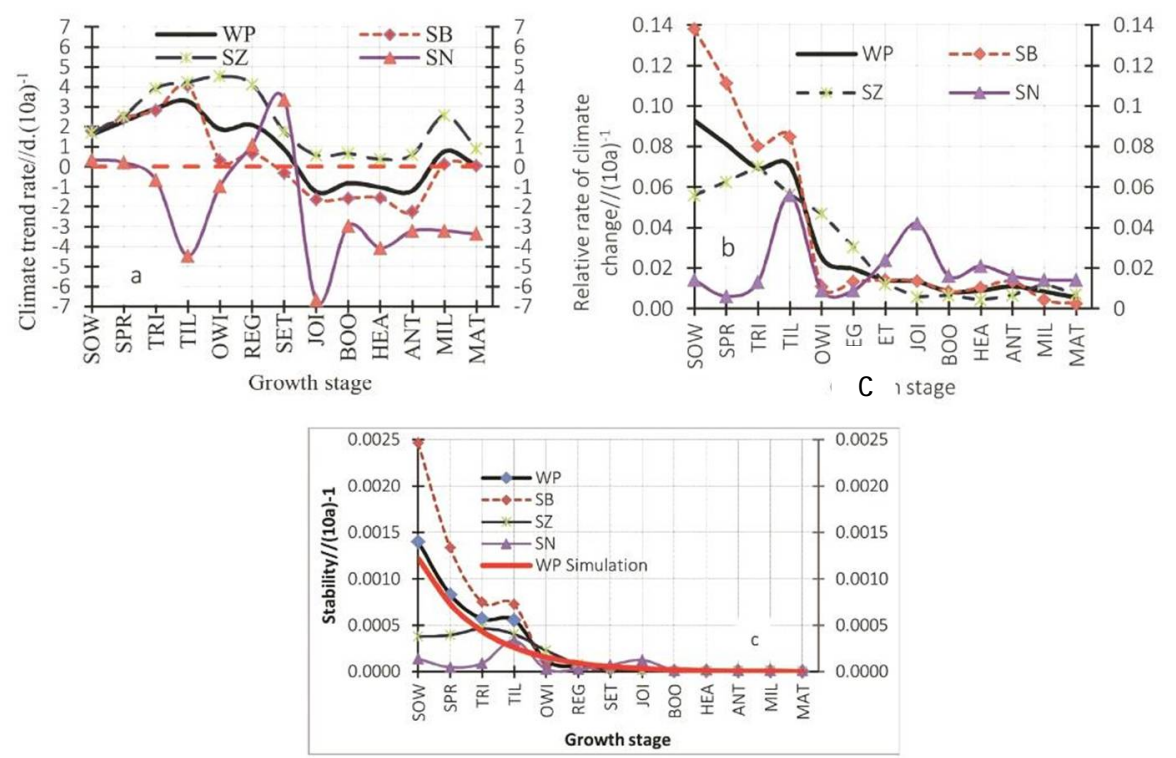

Fig. 4. characteristics of climate change on the growth stage. 
time. The change rate from jointing to mature approximated a straight line and remained low indicating that the influence of climate change on the starting of reproductive stages was obviously smaller than that on vegetative stages. It is found from Figure 4 that the starting time of stages tended to be stable with time. After jointing, the starting time of the whole province tended to be constant. This indicated that the starting time of stages after jointing was more stabilized. The best time for the adjustment of growth status was found before jointing. It is found by numerical simulation that the correlation between stability and the number of stages could be described by an S-shaped curve (Fig. 4). The relation is expressed as:

$$
\mathrm{STA}_{\mathrm{wp}}=\frac{1}{1+\mathrm{e}^{6.191399-0.514882981 \mathrm{i}}}
$$

where $\mathrm{R}=0.97264>\mathrm{RN}-2=11, \mathrm{a}=0.001=0.801$. The extreme significance test was passed, which indicated that the stability of the starting time of the stages in winter wheat was consistent with the general development rule of the crops. The stability at the level of over $95 \%$ was considered as statistical stability. It is calculated by Eq. (19) that $\mathrm{ND}=7$. That means the starting time of stages after setting was stabilized theoretically.

(1) Growth-stage factor in the prediction model for winter wheat was studied. According to the relationship between the length of the early stages and the later states, the relative importance of the factors of growth stage was analyzed by path analysis method. The factors were ranked from left to right in the decreasing order of relative importance:

$$
\begin{aligned}
& \mathrm{YLS}_{\mathrm{wp} 5,6}=70.67661285-0.888414322 \mathrm{YLS}_{\mathrm{wp} 4,5} \\
& \mathrm{YLS}_{\mathrm{wp} 6,7}=24.65062141-0.552103697 \mathrm{YL}_{\mathrm{Swp} 3,4} \\
& \mathrm{YLS}_{\mathrm{wp} 7,8}=28.60384-0.932581843 \mathrm{YLS}_{\mathrm{wp} 1,2} \\
& \mathrm{YLS}_{\mathrm{wp} 8,9}=41.24155426-0.361713595 \mathrm{YLS}_{\mathrm{wp} 5,6}-0.260812953 \mathrm{YLS}_{\mathrm{wp} 7,8} \\
& \mathrm{YLS}_{\mathrm{wp} 9,10}=6.969418049+0.10869614 \mathrm{YLS}_{\mathrm{wp} 8,9} \\
& \mathrm{YLS}_{\mathrm{wp} 10,11}=1.587552547+0.529483739 \mathrm{YLS}_{\mathrm{wp} 9,10} \\
& \mathrm{YLS}_{\mathrm{wp} 11,12}=32.36779785-0.619757753 \mathrm{YLS}_{\mathrm{wp} 7,8} \\
& \mathrm{YLS}_{\mathrm{wp} 12,13}=22.82078552-0.174384389 \mathrm{YLS}_{\mathrm{wp} 11,12}-0.29539588 \mathrm{YLS}_{\mathrm{wp} 2,3}
\end{aligned}
$$

Eqs. (20) - (27) all passed the significance test at RN-2 $=30$, a $=0.05, F(2,29)$, a $=0.05$. It can be seen from Eqs. (20) - (27) that the lengths of the stages before winter were not linearly correlated. After winter, the length of the stages was correlated with the length of one or several stages before winter. Thus, it is possible to predict the variation of the length of future stages according to the length of the stages in the early period. The starting time of the stages can be regulated by adopting proper field management measures. There was a certain linear correlation between the lengths of early and later stages (except that from sprouting to triphyllous). If the early stages were prolonged, the later stages would be shortened. That means the winter wheat can spontaneously adjust the length of the entire growth stage to ensure the relative stability of the starting time of later stages.

(2) Meteorological factor in the prediction model for winter wheat according to the relationship between the length of the i-th stage and the meteorological factors in the i-th stage (Table 2), the relative importance of the factors could be determined by path analysis method. The 
factors were ranked from left to right in the decreasing order of relative importance:

$$
\begin{aligned}
& \mathrm{YLM}_{\mathrm{wp} 1,2}=1.917521+0.030442 \mathrm{X}_{1,2,1}+0.030442 \mathrm{X}_{1,2,13} \\
& \mathrm{YLM}_{\mathrm{wp} 2,3}=9.469150-0.031584 \mathrm{X}_{2,3,3} \\
& \mathrm{YLM}_{\mathrm{wp} 3,4}=1.988606+0.0798603 \mathrm{X}_{3,4,13}+1.020145 \mathrm{X}_{3,4,9}+1.875151 \mathrm{X}_{3,4,10}+0.074399 \mathrm{X}_{3,4,14} \\
& +4.947742 \mathrm{X}_{3,4,12}+0.012791 \mathrm{X}_{3,4,1}+0.358599 \mathrm{X}_{3,4,11}-0.043665 \mathrm{X}_{3,4,8} \\
& \mathrm{YLM}_{\mathrm{wp} 4,5}=0.729705-3.119729 \mathrm{X}_{4,5,6}+2.461189 \mathrm{X}_{4,5,7}+2.502288 \mathrm{X}_{4,5,4}-1.653348 \mathrm{X}_{4,5,5}+0.117807 \mathrm{X}_{4,5,13} \\
& +1.119065 \mathrm{X}_{4,5,9}+0.091728 \mathrm{X}_{4,5,14}+2.405477 \mathrm{X}_{4,5,10}+0.301433 \mathrm{X}_{4,5,3}-0.027664 \mathrm{X}_{4,5,1} \\
& +1.702771 \mathrm{X}_{4,5,11}-0.022462 \mathrm{X}_{4,5,8}+0.204160 \mathrm{X}_{4,5,2} \\
& \mathrm{YLM}_{\mathrm{wp} 5,6}=3.838658-3.009913 \mathrm{X}_{5,6,6}+1.622691 X_{5,6,7}+1.610181 \mathrm{X}_{5,6,5}+0.996326 \mathrm{X}_{5,6,9} \\
& +0.071547 \mathrm{X}_{5,6,13}-0.028257 \mathrm{X}_{5,6,2} \\
& \mathrm{YLM}_{\mathrm{wp} 6,7}=1.374202+0.077516 \mathrm{X}_{6,7,13}+0.088512 \mathrm{X}_{6,7,14}+0.803000 \mathrm{X}_{6,7,10}+0.017446 \mathrm{X}_{6,7,1} \\
& +0.838765 \mathrm{X}_{6,7,11}+0.022182 \mathrm{X}_{6,7,8}-0.016893 \mathrm{X}_{6,7,7}+0.007515 \mathrm{X}_{6,7,2} \\
& \mathrm{YLM}_{\mathrm{wp} 7,8}=2.296793+0.086164 \mathrm{X}_{7,8,14}+0.053995 \mathrm{X}_{7,8,13}+1.455827 \mathrm{X}_{7,8,11}+0.024436 \mathrm{X}_{7,8,1} \\
& +0.286586 \mathrm{X}_{7,8,9}+0.011249 \mathrm{X}_{7,8,8}+0.194130 \mathrm{X}_{7,8,10} \\
& \mathrm{YLM}_{\text {wp } 8,9}=-11.651464+0.059482 \mathrm{X}_{8,9,1}+0.024112 \mathrm{X}_{8,9,13}+0.022447 \mathrm{X}_{8,9,8}+0.058991 \mathrm{X}_{8,9,6} \\
& +0.033090 \mathrm{X}_{8,9,7}+0.637912 \mathrm{X}_{8,9,9}-0.165461 \mathrm{X}_{8,9,11}-0.294605 \mathrm{X}_{8,9,10}+0.140402 \mathrm{X}_{8,9,14} \\
& \mathrm{YLM}_{\mathrm{wp} 9,10}=0.450207+0.144430 \mathrm{X}_{, 10,14}+0.034151 \mathrm{X}_{, 10,1}+0.442627 \mathrm{X}_{, 10,11}+0.085183 \mathrm{X}_{, 10,9} \\
& \mathrm{YLM}_{\mathrm{wp} 10,11}=0.424120+0.040744 \mathrm{X}_{10,11,1}+0.112303 \mathrm{X}_{10,11,14}-0.010250 \mathrm{X}_{10,11,13} \\
& \mathrm{YLM}_{\text {wp 11,12 }}=-0.650809+0.043389 \mathrm{X}_{11,12,1}+0.016977 \mathrm{X}_{11,12,8}+0.527284 \mathrm{X}_{11,12,9}-0.134018 \mathrm{X}_{11,12,10} \\
& -0.285981 X_{11,12,11}-0.838162 X_{11,12,12}+0.0430845 X_{11,12,14} \\
& \mathrm{YLM}_{\mathrm{wp} 12,13}=0.765883+0.038648 \mathrm{X}_{12,13,1}+0.003365 \mathrm{X}_{12,13,13}+0.013186 \mathrm{X}_{12,13,8}
\end{aligned}
$$

Eqs. (28)-(39) passed the significance test at $\mathrm{RN}-2=30, \mathrm{a}=0.05, \mathrm{~F}(2,29), \mathrm{a}=0.05$. It is known from Eqs. (28)-(39) that the length of all stages was correlated with the meteorological conditions for winter wheat, although the dominant meteorological factors varied with specific stages. Based on the weather forecast and Eqs. (28)-(39), the influence of future meteorological conditions on the length of growth stages of winter wheat could be calculated, see Eq. (9). The appropriate cultivation measures can be adopted depending on the influence degree to ensure the relative stability of the growth stage of winter wheat.

Table 2. Meteorological factors.

\begin{tabular}{clllllcc}
\hline Factor & $\begin{array}{l}\text { Accumulated } \\
\text { Temp. }\end{array}$ & $\begin{array}{l}\text { Negative } \\
\text { Accumu- } \\
\text { lated Temp. }\end{array}$ & $\begin{array}{l}\mathrm{O} \mathrm{cm} \\
\text { ground } \\
\text { temp. }\end{array}$ & $\begin{array}{l}5 \mathrm{~cm} \\
\text { ground } \\
\text { temp. }\end{array}$ & $\begin{array}{l}10 \mathrm{~cm} \\
\text { ground } \\
\text { temp. }\end{array}$ & $\begin{array}{c}15 \mathrm{~cm} \\
\text { ground } \\
\text { temp. }\end{array}$ & $\begin{array}{c}20 \mathrm{~cm} \text { ground } \\
\text { Temp. }\end{array}$ \\
\hline Code & $\mathrm{X}_{\mathrm{i}, 1}$ & $\mathrm{X}_{\mathrm{i}, 2}$ & $\mathrm{X}_{\mathrm{i}, 3}$ & $\mathrm{X}_{\mathrm{i}, 4}$ & $\mathrm{X}_{\mathrm{i}, 5}$ & $\mathrm{X}_{\mathrm{i}, 6}$ & $\mathrm{X}_{\mathrm{i}, 7}$ \\
Factor & precipitation & $\begin{array}{l}\text { Light rain } \\
\text { days }\end{array}$ & $\begin{array}{l}\text { Small to } \\
\text { moderate } \\
\text { rain days }\end{array}$ & $\begin{array}{l}\text { Moderate } \\
\text { rain days }\end{array}$ & $\begin{array}{l}\text { The } \\
\text { heavy } \\
\text { rain days }\end{array}$ & $\begin{array}{c}\text { sunshine } \\
\text { duration }\end{array}$ & wind speed \\
Code & $\mathrm{X}_{\mathrm{i}, 8}$ & $\mathrm{X}_{\mathrm{i}, 9}$ & $\mathrm{X}_{\mathrm{i}, 10}$ & $\mathrm{X}_{\mathrm{i}, 11}$ & $\mathrm{X}_{\mathrm{i}, 12}$ & $\mathrm{X}_{\mathrm{i}, 13}$ & $\mathrm{X}_{\mathrm{i}, 14}$ \\
\hline
\end{tabular}


(3) There are many ensemble forecast methods that integrate the conclusions from various forecasts. The coefficients were determined by using weighted mean method in this article:

$$
\begin{aligned}
& \mathrm{YL}_{\mathrm{i}}=0.5 \times \mathrm{YLS}_{\mathrm{i}}+0.5 \times \mathrm{YLM}_{\mathrm{i}} \\
& \mathrm{YD}_{\mathrm{i}+1}=\mathrm{YD}_{\mathrm{i}}+\mathrm{YL}_{\mathrm{i}+1} \ldots \\
& \Delta \mathrm{YD}_{\mathrm{i}+1}=\mathrm{YD}_{\mathrm{i}+1}-\mathrm{YD}_{\mathrm{i}+1}
\end{aligned}
$$

The deviation of the growth stage from the average over the years can be calculated using Eq. (42). The targeted regulatory measures can be implemented to ensure the relative stability of the growth stage of winter wheat.

(1) The length of the stages before regreening mainly showed longitudinal variation and latitudinal variation after regreening, which means the key stages of winter wheat varied with latitude. Therefore, the influence of latitude should be considered in variety introduction to different regions and the adjustment of planting structure.

(2) The lengths of various stages of winter wheat were linearly correlated. The degree of correlation decreased with the prolonging of the intervals between the stages. If the early stages were prolonged, the later stages would be shortened. Therefore, the potential influence of adjacent stages should be taken into account when adjusting the individual structure. Proper management measures should be implemented to reduce the adverse impacts.

(3) Through the artificial adjustment of the sowing date and the spontaneous adaptation of winter wheat in Jiangsu showed vegetative growth and slow changes in the phase of reproductive growth. That means the length of the growth stage tended to be more stable with time. Therefore, the key period for the adjustment of the length of growth stage by cultivation measures is the phase of vegetative growth.

(4) The main reason for the interannual fluctuation of winter wheat yield is the disastrous weather during the growth stage of winter wheat, such as continuous drought or rain. Therefore, resistance cultivation is important measures to combat the climate change. The focus is to strengthen the monitoring and prewarning ability on major meteorological disasters occurring during the growth of winter wheat. The countermeasures against disasters such as artificial precipitation and hail mitigation should be implemented to ensure the relative stability of the growth stage and a balance of growth status. In this way, the goals of high yield and quality of winter wheat can be achieved.

It is the development direction of scientific cultivation to improve the management level of cultivation field by predicting the change of wheat growth process. It is a feasible method to forecast by meteorological conditions and pre-growth conditions, but how to establish a scientific and reasonable model needs further exploration.

\section{Acknowledgements}

This work was funded by the Jiangsu province Meteorological Scientific Research Open Fund (Grant No. 200712: Agricultural meteorological disaster weather pattern library and Grant No. 200807: Research and application with high yield and good quality cultivation techniques on wheat and barley in Lixiahe wetland).

\section{References}

China Meteorological Administration 1993. Agrometeorological specification (Volume), China Meteorological Press 11.

Gao DR, Zhang X, Zhang BQ, Zhu DM and Lv GF 2013. Concept on wheat quality improvement in middle and lower reaches of Yangtze River Valle. J. Triticeae Crops 4: 840-844. 
Johnen T, Boettcher U, Kage H 2014. An analysis of factors determining spatial variable grain yield of winter wheat. European J. Agron. 52: 297-306.

Lu CH and Fan L 2013. Winter wheat yield potentials and yield gaps in the North China Plain. Field Crops Res. 143: 98-105.

Shang ZT, Jiang D and He L 2013. The research development about influence of climatic change on wheat production. Chinese Agricul. Science Bulletin 21: 6-11.

Shang ZT, Wu JZ, Jiang MS, Li JY, Yu QP, Wang SQ 2007. Analysis on influence of wheat growth on yield and quality. J. Anhui Agri. Sci. 28: 8826-28829.

(Manuscript received on 19 May, 2021; revised on 22 September, 2021) 